Article

\title{
Reactive Extraction of Lactic Acid, Formic Acid and Acetic Acid from Aqueous Solutions with Tri-n-octylamine/1-Octanol/n-Undecane
}

\author{
Nuttakul Mungma, Marlene Kienberger * and Matthäus Siebenhofer \\ Institute of Chemical Engineering and Environmental Technology, Graz University of Technology, 8010 Graz, \\ Austria; m.nuttakul@gmail.com (N.M.); m.siebenhofer@tugraz.at (M.S.) \\ * Correspondence: marlene.kienberger@tugraz.at
}

Received: 19 February 2019; Accepted: 19 April 2019; Published: 30 April 2019

check for updates

\begin{abstract}
The present work develops the basics for the isolation of lactic acid, acetic acid and formic acid from a single as well as a mixed feed stream, as is present, for example, in fermentation broth for lactic acid production. Modelling of the phase equilibria data is performed using the law of mass action and shows that the acids are extracted according to their $\mathrm{pk}_{\mathrm{a}}$ value, where formic acid is preferably extracted in comparison to lactic and acetic acid. Back-extraction was performed by $1 \mathrm{M} \mathrm{NaHCO}_{3}$ solution and shows the same tendency regarding the $\mathrm{pk}_{\mathrm{a}}$ value. Based on lactic acid, the solvent phase composition, consisting of tri- $n$-octylamine/1-octanol/ $n$-undecane, was optimized in terms of the distribution coefficient. The data clearly indicate that, compared to physical extraction, mass transfer can be massively enhanced by reactive extraction. With increasing tri- $n$-octylamine and 1-octanol concentration, the equilibrium constant increases. However, even when mass transfer increases, tri- $n$-octylamine concentrations above $40 \mathrm{wt} \%$, lead to third phase formation, which needs to be prevented for technical application. The presented data are the basis for the transfer to liquid membrane permeation, which enables the handling of emulsion tending systems.
\end{abstract}

Keywords: carboxylic acids; lactic acid recovery; reactive extraction; phase equilibrium

\section{Introduction}

The change from fossil fuel sources to renewables not only needs to be discussed in terms of energy, but also in terms of fuel and chemicals. In this context, the replacement of bulk chemicals derived from fossil fuels with bulk chemicals from renewable sources needs to be targeted. Lactic acid is already obtained today from renewable resources, but its downstream processing is costly and the process intensification, together with the use of different sources for lactic acid, may be targeted in the future. Lactic acid is of particular interest as a growth rate of $20 \%$ per year is expected due to the use as the monomer for poly lactic acid (PLA) production. [1,2].

Poly lactic acid production requires lactic acid with a purity $>95 \%$ [3], which can be obtained by fermentation. Lactic acid is produced either by chemical synthesis or by fermentation of carbon-based resources. Currently, approximately $90 \%$ of lactic acid is produced by microbial fermentation. Sugars and carbohydrate sources for pentose, hexoses and lignocellulosic materials are used as a substrate [4]. The benefits of lactic acid synthesis by microbial fermentation are the low environmental impact, low operation temperature, low energy requirements and high product purity [5]. However, downstream processing requires massive quantities of neutralizing agents, as lactic acid is precipitated by neutralization with lime and is then re-dissolved by strong acids, mostly sulfuric acid, which consequently generates huge quantities of calcium sulfate as a byproduct to be disposed of $[6,7]$. Separation and purification of lactic acid from fermentation broth accounts for approximately $50 \%$ of 
the total production costs [8]. Depending on the microorganism used for the fermentation, acetic acid and formic acid are produced as by-products during fermentation [9].

Much attention has been focused on the process intensification of the isolation process to reduce the production costs. Several techniques have been developed and reported, such as fluidized bed fermentation with immobilized cells making use of in situ weak anion exchange resin separation with Amberlite IRA-67 [10], nanofiltration [11] or electrodialysis for the isolation of lactic acid [12].

In situ liquid-liquid extraction is expected to be an efficient technology for the recovery of carboxylic acids from fermentation broth [13]. The acid is transferred from the fermentation broth into a solvent phase, thus demanding bio-compatibility of the solvent [14]. Liquid-liquid extraction of carboxylic acids is well established, and reactive extraction is a promising approach in terms of both, selective separation and process intensification. Depending on the solvent, two extraction mechanisms can be distinguished. Generally, an ion exchange, in which the solvent acts as a liquid ion-exchanger, is performed, and the second mechanism uses chelating and/or solvating solvents [15]. During a solvating or chelating reaction, one or more molecules of water are replaced by the extractant, forming a complex that has an increased solubility in the solvent phase [16]. However, in situ extraction of valuables from a fermentation broth is in general accompanied with third phaseor crud formation, which prevents the use of a conventional extraction process [17]. Therefore, supported liquid membrane permeation was shown to be effective for the purpose of emulsion prevention in highly emulsion tending systems and can help to overcome the drawback of emulsion/crud formation when bio-based process streams are targeted [18].

Tertiary amines with $C_{7}$ to $C_{12}$ alkyl groups have been reported to be the best ion exchange-type extractants for carboxylic acids [19]. Due to their high viscosity and the low polarity of the tertiary amine, a diluent is generally used. The diluent influences the solvation by improving its physicochemical properties. Diluents may be categorized by their polarity as active (polar) and inert (non-polar) diluent. Because of the functional groups, an active diluent is polar, examples for active diluents are chlorinated hydrocarbons, alcohols and ketones [20]. Research for carboxylic acid extraction by tertiary amines uses generally long-chained alcohols, since they provide a good solvation media for an ion-pair such as an acid-amine salt and low water miscibility [21]. Several studies dealing with the reactive extraction of lactic acids using tri- $n$-octylamine (TOA) with active or inert diluents have been reported in the literature [22-24]. The acid extraction efficiency was found to increase with increasing active diluent. The highest extraction efficiency was reported using 97\% TOA diluted in 1-octanol [22]. However, its viscosity is expected to hinder the mass transfer at the interface. Inert diluents (non-polar) like alkanes and benzene, on the other hand, provide lower viscosity, but lead to a poor transfer into the organic phase of the polar salt [25].

To optimize a reactive extraction process, the extraction equilibrium constant is required. The present work aims to study the phase equilibrium behavior of the reactive liquid-liquid extraction of lactic acid, formic acid and acetic acid from a simulated fermentation broth by using mixtures of tri- $n$-octylamine, 1 -octanol and $n$-undecane. To ensure that no crud formation occurs, and hence that the phase equilibria data are measured correctly, pure substances are used in the present study. Phase equilibrium of the single acids is measured in dependence on the composition of the solvent phase and the acid concentration. Furthermore, the selective separation from a multi-acid feed is investigated and discussed. An equilibrium model based on the law of mass action is applied to describe the data.

\section{Materials and Methods}

\subsection{Materials}

For the preparation of the aqueous feed phase, de-ionized water and either a single acid or all three acids were mixed at room temperature. Acetic acid (CAS 64-19-7) and formic acid (CAS 64-18-16) with a purity of $>99 \%$ were purchased from Chem-Lab. Lactic acid (CAS 79-33-4) with a purity of $80 \%$, purchased from Carl Roth, was used. The single acid solution contained the respective acid with a 
concentration between $0.2-1.0 \mathrm{~mol} / \mathrm{L}$. The multi acid solution contained lactic acid with a concentration of $0.7 \mathrm{~mol} / \mathrm{L}$, formic acid with a concentration of $0.04 \mathrm{~mol} / \mathrm{L}$ and acetic acid with a concentration of $0.07 \mathrm{~mol} / \mathrm{L}$ with respect to the acid concentration occurring during the fermentation process $[9,26]$.

The solvent phase contained tri- $n$-octylamine (CAS 1116-76-3) with a purity of $97 \%$, purchased from Acros organics, $n$-undecane (CAS 1120-21-4) with a purity $>95 \%$ and 1-octanol (CAS 111-87-5) with a purity of $>99 \%$, both purchased from Sigma Aldrich. The solvent phase was prepared by mixing the components at room temperature. The stripping solution contained de-ionized water and sodium hydrogen carbonate with a purity of $99.5 \%$ (CAS 144-55-8), purchased from Carl Roth. All chemicals were used as received.

\subsection{Analytics}

The concentration of the respective acid in the aqueous phases was determined by high-performance liquid chromatography (HPLC, Dionex, Frankfurt, Germany). The HPLC systems consisted of a REZEX-ROA column and an UV/VIS detector, detecting at a wavelength of $210 \mathrm{~nm}$. As mobile phase, $0.005 \mathrm{M} \mathrm{H}_{2} \mathrm{SO}_{4}$ in ultrapure water with a flow rate of $0.5 \mathrm{~mL} / \mathrm{min}$ was used. All samples were analyzed at room temperature. The concentration of the extracted acid in the solvent phase was calculated by determining the mass balance.

\subsection{Experimental Setup and Procedure}

The phase equilibrium measurements were performed in a temperature-controlled separation funnel at $25^{\circ} \mathrm{C}$. The ratio between the aqueous and the solvent phase was kept constant at 1 by weight. After transferring the solvent phase and the aqueous phase in the separation funnel, the funnels were shaken with the automatic shaker (Janke \& Kunkel HS-500, Janke \& Kunkel, Staufen im Breisgau, Germany) at $200 \mathrm{rpm}$ for $30 \mathrm{~min}$, this procedure ensures intensive phase contact. Preliminary experiments showed that phase equilibrium is reached after $30 \mathrm{~min}$; however, to ensure phase equilibrium and especially phase separation, the mixture was settled for 3 hours. Within this time period, phase separation was completed for most of the experiments. Some experiments lead to an optically visible third phase. After phase separation, the mass of both phases was recorded and the acid concentrations in the aqueous phase were analyzed with HPLC.

After extraction, the laden solvent phase was contacted with a sodium hydrogen carbonate solution with a concentration of $1 \mathrm{~mol} / \mathrm{L}$ to strip the acid into the stripping phase. The procedure used for the back-extraction process was the same as was used for the extraction step

\section{Results and Discussion}

\subsection{Physical Extraction}

For physical extraction, two different categories of solvent-a non-polar solvent ( $n$-undecane) and a polar solvent (1-octanol) - were used to perform the experiments in order to quantify the effect of physicochemical properties on physical extraction. Since the $\mathrm{pH}<\mathrm{pK}_{\mathrm{a}}$, the distribution coefficient $\left(K_{D \text {,diluent }}\right)$ is a function of the partition coefficient $(P)$ and the dimerization constant $(D)$, and is expressed by Equation (1) [25].

$$
K_{D, \text { diluent }}=P+2 P^{2} D\left[c_{\mathrm{HA}, \mathrm{aq}}\right]
$$

The distribution coefficient $\left(K_{D \text {,diluent }}\right)$ is defined as the ratio of acid in the solvent phase $\left(c_{\mathrm{HA}, \text { sol }}\right)$ and in the aqueous phase $\left(c_{\mathrm{HA}, \mathrm{aq}}\right)$ as given in Equation (2):

$$
K_{D, \text { diluent }}=c_{\mathrm{HA}, \mathrm{sol}} / c_{\mathrm{HA}, \mathrm{aq}}
$$

Phase equilibria data of both solvents were measured by varying the initial acid concentration in the feed phase in a range of $0.2-1 \mathrm{~mol} / \mathrm{L}$. Table 1 summarizes the partition coefficient and the 
dimerization factor of lactic acid, acetic acid and formic acid in dependence on the respective solvent. Physical extraction was found to be very poor in both solvents used. Due to its donor and acceptor characteristics, 1-octanol interacts with the acid by hydrogen bonding and hence provides higher partition coefficients compared to $n$-undecane, for which only nonspecific directional, induction and dispersion forces are employed [25]. In $n$-undecane, formic acid has a dimerization constant of 35.65, while for acetic acid and lactic acid, $D$ was found to be 6.62 and 10.42, respectively. The dimerization constant of formic acid decreases by a factor of 10 when changing the solvent from $n$-undecane to 1 -octanol. It can be concluded that in $n$-undecane, the acid-acid bond is preferred, while acid-solvent hydrogen bonds are observed when 1-octanol was used. These results fit well to the data from the literature. Maurer [27] describes the dimerization by intermolecular hydrogen bonding of acetic acid in low polar solvents.

Table 1. Summary of the calculated partitioning coefficient and dimerization factor for lactic acid, acetic acid and formic acid using $n$-undecane and 1-octanol; $c_{\text {acid,initial }}=0.2-1.0 \mathrm{~mol} / \mathrm{L} ; \mathrm{T}=25{ }^{\circ} \mathrm{C}$; ambient pressure.

\begin{tabular}{cccc}
\hline Acid & Solvent & $\boldsymbol{P}$ & $\boldsymbol{D}(\mathbf{l} / \mathbf{m o l})$ \\
\hline \multirow{2}{*}{ Lactic acid } & n-undecane & 0.06 & 6.62 \\
& 1-octanol & 0.24 & 0.46 \\
\hline \multirow{2}{*}{ Acetic acid } & n-undecane & 0.01 & 10.42 \\
& 1-octanol & 0.49 & 0.30 \\
\hline \multirow{2}{*}{ Formic acid } & n-undecane & 0.03 & 35.65 \\
& 1-octanol & 0.25 & 3.39 \\
\hline
\end{tabular}

\subsection{Reactive Extraction}

Since physical extraction provided low distribution coefficients for carboxylic acids, reactive extraction was applied. Reactive extraction provides high mass transfer and shall provide selective separation by chemical reaction of the constituent with the reactive component of the solvent. Due to its high Brønsted basicity tri- $n$-octylamine (TOA), a tertiary long-chain aliphatic amine, has been reported to provide high distribution coefficients for carboxylic acids [28]. In this work, therefore, TOA was chosen as reactive extractant. Usually, the solvent phase in reactive extraction consists of three components, the reactive extractant, the modifier and the diluent. The purpose of the reactive extractant is the reaction with the targeted substances, the diluent decreases the density and the viscosity, while the modifier increases the solubility of the complex or salt formed in the solvent phase $[22,29,30]$. The influence of the diluent $n$-undecane and the modifier 1-octanol in the solvent phase on the extraction efficiency of lactic acid was investigated further.

\subsubsection{Influence of the Solvent Composition on the Distribution Coefficient}

The TOA concentration was varied between $15-40 \mathrm{wt} \%$ in the presence of 1-octanol diluted in $n$-undecane. The ratio between the modifier, 1-octanol and TOA were kept constant at one by weight for all experiments. This ratio was chosen because at the maximum content of amine and modifier showed to be an optimized solvent composition [31]. However, the concentration of TOA was limited at a maximum of $40 \mathrm{wt} \%$ according to the outcome of a previous study, we found that above that concentration third phase formation occurs. Table 2 summarizes the distribution coefficient and the extraction efficiency of lactic acid with different solvent compositions. The extraction efficiency $(E)$ is expressed in Equation (3).

$$
E=K_{D} /\left(1+K_{D}\right) \times 100
$$

where $K_{D}$ is defined as the ratio of acid concentration in the solvent phase to the acid concentration in the aqueous phase, as described in Equation (2). 
Table 2. Summary of the distribution coefficient, the extraction efficiency and the $\mathrm{pH}$ value in equilibrium for lactic acid with different solvent compositions; $c_{\text {acid,initial }}=0.2-1 \mathrm{~mol} / \mathrm{L} ; \mathrm{T}=25{ }^{\circ} \mathrm{C}$; ambient pressure; solvent:water $=1$.

\begin{tabular}{|c|c|c|c|c|c|c|c|}
\hline $\begin{array}{l}\text { TOA:-1-octanol:n-undecane } \\
\text { (wt } \%)\end{array}$ & $\begin{array}{c}m_{H A, i n} \\
(\mathrm{~g})\end{array}$ & $\begin{array}{c}m_{H A, a q} \\
\text { (g) }\end{array}$ & $\begin{array}{c}c_{\mathrm{HA}, \mathrm{aq}} \\
(\mathrm{mol} / \mathrm{L})\end{array}$ & $\begin{array}{l}c_{\mathrm{HA}, \mathrm{sol}} \\
(\mathrm{mol} / \mathrm{L})\end{array}$ & $K_{D}$ & $E(\%)$ & $p H$ \\
\hline \multirow{4}{*}{$15: 15: 70$} & 10.01 & 8.97 & 0.092 & 0.123 & 1.35 & 57.5 & 2.42 \\
\hline & 10.01 & 9.29 & 0.236 & 0.236 & 1.01 & 50.2 & 2.15 \\
\hline & 9.99 & 9.73 & 0.414 & 0.326 & 0.83 & 45.4 & 1.99 \\
\hline & 9.99 & 9.06 & 0.599 & 0.408 & 0.69 & 40.7 & 1.82 \\
\hline \multirow{4}{*}{$25: 25: 50$} & 10.01 & 9.42 & 0.037 & 0.178 & 4.89 & 83.0 & 2.76 \\
\hline & 10.01 & 9.42 & 0.099 & 0.372 & 3.75 & 78.9 & 2.44 \\
\hline & 9.99 & 9.29 & 0.189 & 0.551 & 2.91 & 74.4 & 2.24 \\
\hline & 10.01 & 8.85 & 0.324 & 0.683 & 2.11 & 67.8 & 2.11 \\
\hline \multirow{4}{*}{$40: 40: 20$} & 9.99 & 9.23 & 0.006 & 0.209 & 34.79 & 97.2 & 3.59 \\
\hline & 9.99 & 8.90 & 0.020 & 0.452 & 22.18 & 95.7 & 3.18 \\
\hline & 10.01 & 8.31 & 0.045 & 0.695 & 15.76 & 94.0 & 2.94 \\
\hline & 9.99 & 8.39 & 0.079 & 0.923 & 11.71 & 92.1 & 2.73 \\
\hline
\end{tabular}

For all solvent compositions, the distribution coefficient decreased with increasing initial acid concentration. This result is beneficial for the application to a fermentation broth, as the acid concentration, is generally not higher than $10 \mathrm{wt} \%$. The distribution coefficient for the solvent consisting of 15:15 TOA:1-octanol, diluted in $n$-undecane was in the range between $0.69-1.35$, and for a solvent composition of 25:25 TOA:1-octanol by weight, diluted in $n$-undecane, the distribution coefficient varied between 2.11-4.89. The highest distribution coefficient, which was between 11.71 and 34.79 , was achieved with a solvent, consisting of 40:40 TOA:1-octanol by weight, diluted in $n$-undecane, Kyuchoukov et al. obtained comparable results when a similar solvent composition consisting of TOA:1-octanol diluted in dodecane was used for the extraction of lactic acid [32]. As expected from results gained in the physical extraction, the diluent does not influence the phase equilibrium when reactive extraction is concerned.

Yamamoto [33] et al. reported the improvement of the extraction ability of lactic acid by adding decanol as modifier into di-n-octylamine (DOA). They reported the tendency of third phase formation when a non-polar diluent is used. Prevention of the third phase formation was ensured by setting the volume fraction of the modifier $>10 \%$ when using a solvent composition of di- $n$-octylamine (DOA). Secondary and tertiary amines behave differently in terms of emulsion formation, also in the present work we saw the formation of a stable third phase for all experiments having a TOA concentration $\geq 40 \mathrm{wt} \%$. This undesired third phase is impossible to operate with; the emulsion split neither due to gravity nor due to centrifugal forces. Measurement of phase equilibrium is hence not possible. The formation of a third phase was further observed in experiments using $25 \mathrm{wt} \%$ TOA and an acid concentration above $0.8 \mathrm{~mol} / \mathrm{L}$. By increasing the acid concentration, the formation of ring structures and hence emulsions because of the substitution of solvent molecules with water is most likely [34]. Emulsion formation between formic acid and terpenyl amine was also observed by Schulz [35] et al. This could be because of the hydrophilic and lipophilic structure of the structure formed. Figure 1 shows the stable third phase in the solvent phase. 


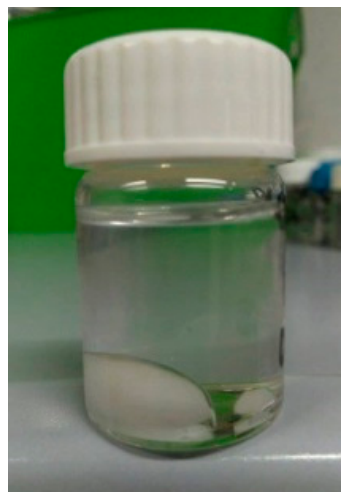

Figure 1. Third phase in the solvent phase after the removal of the aqueous phase for formic acid with 25:25 TOA:1-octanol by weight, diluted in $n$-undecane; $c_{\text {formic, initial }}=0.8 \mathrm{~mol} / \mathrm{L} ; \mathrm{T}=25{ }^{\circ} \mathrm{C}$; ambient pressure.

\subsubsection{Determination of the Extraction Equilibrium Constant and the Degree of Association}

To be able to determine the extraction equilibrium constant $\left(K_{E}\right)$ and the degree of association $(n)$, the law of mass action was applied. TOA has been reported to extract the non-dissociated form of the mono-carboxylic acid when the $\mathrm{pH}<\mathrm{pK}_{\mathrm{a}}$ [36]. The general reaction equation of carboxylic acids (HA) with the reactive component tri- $n$-octylamine (TOA), is expressed as given in Equation (4).

$$
n \mathrm{HA}_{\mathrm{aq}}+\mathrm{TOA}_{\mathrm{sol}} \leftrightarrow\left(\mathrm{TOA}(\mathrm{HA})_{\mathrm{n}}\right)_{\text {sol }}
$$

where $n$ represents the degree of association of acid per one molecule of TOA.

Since the solvent composition, as well as the acid influence the equilibrium constant [29], the quantitative interpretation of the extraction equilibrium constant can be represented as

$$
K_{E}=c(\mathrm{TOA}(\mathrm{LA}) n, \mathrm{sol}) /\left(c_{\mathrm{HA}, \mathrm{aq}}{ }^{\wedge} \cdot c_{\mathrm{TOA}, \mathrm{sol}}\right)
$$

it also has to be taken into account that the non-dissociated lactic acid is extracted into the solvent phase due to the additional adduct formation with the extractant. By substitution of $c(\mathrm{TOA}(\mathrm{LA}) n, \mathrm{sol})=$ $c_{\mathrm{HA}, \mathrm{sol}} / n$ and $c_{\mathrm{TOA}, \mathrm{sol}}=c_{\mathrm{TOA}, \mathrm{sol}, 0}-c_{\mathrm{HA}, \mathrm{sol}} / n$, Equation (5) becomes:

$$
K_{E}=c_{\mathrm{HA}, \mathrm{sol}} /\left(n \cdot c_{\mathrm{HA}, \mathrm{aq}, \text { nondiss }} \hat{n} \cdot\left(c_{\mathrm{TOA}, \mathrm{sol}, 0}-c_{\mathrm{HA}, \mathrm{sol}} / n\right)\right)
$$

LUX et al. [37] reported the degree of dissociation decreases with increasing acid concentration. Therefore, at low acid concentration, this term cannot be neglected. The non-dissociated form of the mono-carboxylic acid is expressed by

$$
c_{\mathrm{HA}, \mathrm{aq}, \text { nondiss }}=c_{\mathrm{HA}, \mathrm{aq}}(1-\alpha)
$$

where $\alpha$ is the degree of dissociation defined as

$$
\alpha=\left(-K_{\text {diss }} \pm \sqrt{ }\left(K_{\text {diss }}{ }^{\wedge} 2+4 c_{\mathrm{HA}, 0} \cdot K_{\text {diss }}\right)\right) /\left(2 \cdot c_{\mathrm{HA}, 0}\right)
$$

subsequently, Equations (9) and (10) represent the equilibrium reaction.

$$
\begin{gathered}
\left.c_{\mathrm{HA}, \mathrm{sol}}=\left(n \cdot K_{\mathrm{st}} \cdot c^{n}{ }_{\mathrm{HA}, \mathrm{aq}, \text { nondiss }}\right) \cdot \mathcal{C}_{\mathrm{TOA}, 0}\right) /\left(1+K_{\mathrm{st}} \cdot c^{n}{ }_{\mathrm{HA}, \mathrm{aq}, \text { nondiss }}\right) \\
1 / c_{\mathrm{HA}, \mathrm{sol}}=1 /\left(n \cdot K_{\mathrm{st}} \cdot c^{n}{ }_{\mathrm{HA}, \mathrm{aq}, \text { nondiss }} \cdot{ }_{\mathrm{TOA}, 0}\right)+\left(1 / \mathcal{C}_{\mathrm{TOA}, 0} \cdot n\right)
\end{gathered}
$$

With a specified initial concentration of TOA and varying the degree of association, a linear fitted curve can be plot using professional graphics software to estimate the equilibrium constants. 
The graphical representation is proceeded to determine the values of $K_{E}$ and $n$ for the different solvent system as depicted in Figures 2-4. As can be seen, the results fit well to the calculation in Equation (10) and give access to the calculation of the equilibrium constant in both, the binary and the ternary solvent system.

Table 3 summarizes the equilibrium constant, the degree of association and the loading ration $(Z)$ in dependence on the solvent composition. The modeled data point out a significant difference in the degree of association for a solvent composed of 1 -octanol and $n$-undecane. The value of $n \approx 1$ estimated from TOA with 1-octanol suggests the 1:1 adduction of lactic acid to TOA, whereas $n>1$ was found for the solvent composed with $n$-undecane.

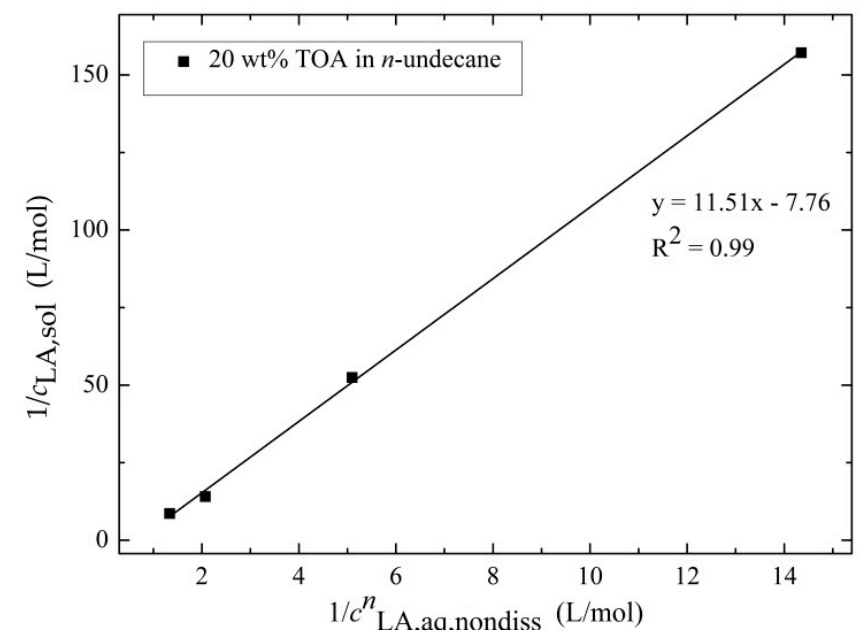

Figure 2. Determination of the extraction equilibrium constant and the degree of acid association of lactic acid (solvent with $20 \mathrm{wt} \%$ TOA in $n$-undecane; $\mathrm{T}=25^{\circ} \mathrm{C}$; ambient pressure) according to Equation (10).

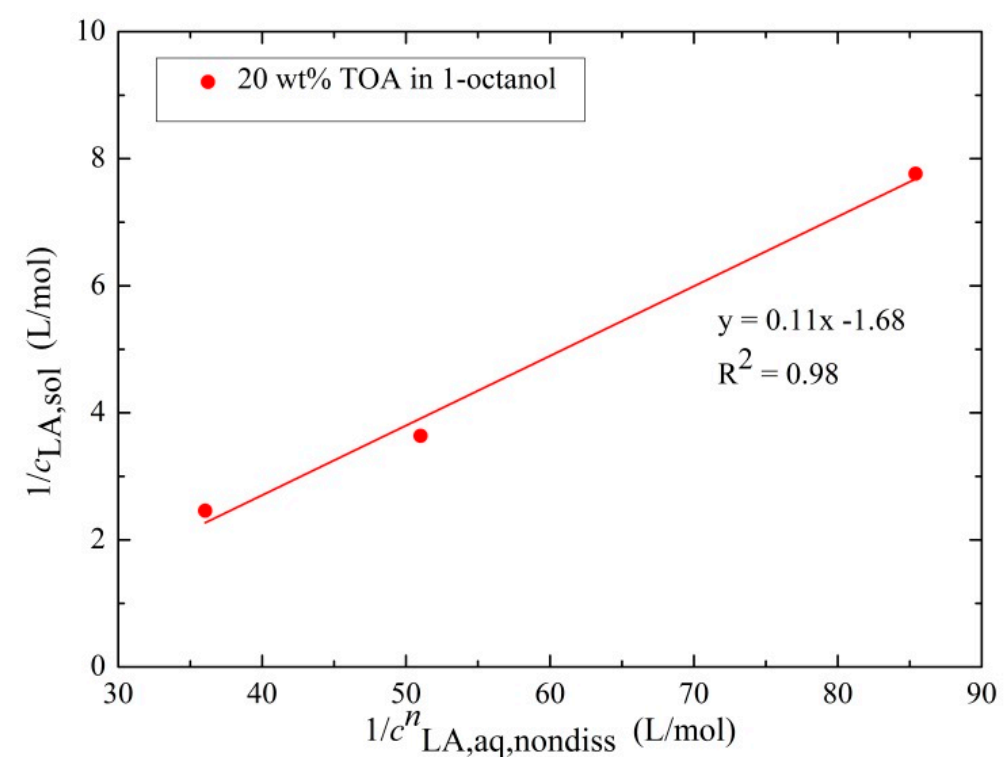

Figure 3. Determination of the extraction equilibrium constant and the degree of acid association of lactic acid (solvent with $20 \mathrm{wt} \% \mathrm{TOA}$ in 1-octanol; $\mathrm{T}=25^{\circ} \mathrm{C}$; ambient pressure) according to Equation (10). 


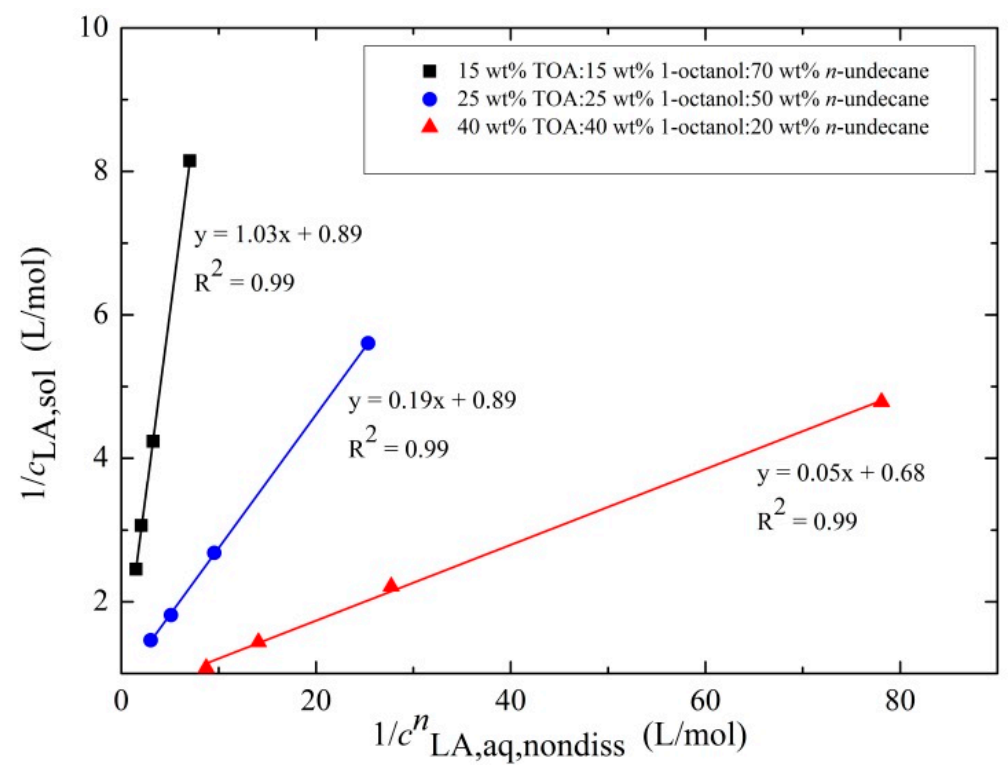

Figure 4. Determination of the extraction equilibrium constant and the degree of acid association of lactic acid ( $\mathrm{T}=25^{\circ} \mathrm{C}$; ambient pressure) according to Equation (10).

Table 3. Summary of calculated $K_{E}$ and $n$ for reactive extraction of lactic acid, acetic acid and formic acid with different ratios of TOA:1-octanol and $n$-undecane; $c_{\text {acid,initial }}=0.2-1.0 \mathrm{~mol} / \mathrm{L} ; \mathrm{T}=25^{\circ} \mathrm{C}$; ambient pressure; solvent:water $=1$.

\begin{tabular}{|c|c|c|c|c|c|c|c|}
\hline $\begin{array}{c}\text { TOA } \\
(\mathbf{w t} \%)\end{array}$ & $\begin{array}{c}\text { 1-octanol } \\
(w t \%)\end{array}$ & $\begin{array}{c}n \text {-undecane } \\
(w \mathrm{t} \%)\end{array}$ & $\begin{array}{c}\text { Viscosity } \\
\left(\mathrm{m} \cdot \mathrm{Pas}, 20^{\circ} \mathrm{C}\right)\end{array}$ & Acid & $n$ & $K_{E}$ & $Z$ \\
\hline \multirow{3}{*}{15} & \multirow{3}{*}{15} & \multirow{3}{*}{70} & \multirow{3}{*}{2.34} & Lactic & 0.81 & 3.53 & $0.36-1.99$ \\
\hline & & & & Acetic & 1.11 & 2.16 & $0.23-1.15$ \\
\hline & & & & Formic & 1.55 & 27.79 & $0.49-1.68$ \\
\hline \multirow{3}{*}{25} & \multirow{3}{*}{25} & \multirow{3}{*}{50} & \multirow{3}{*}{2.92} & Lactic * & 0.97 & 9.73 & $0.31-1.99$ \\
\hline & & & & Acetic * & 1.55 & 5.25 & $0.20-1.06$ \\
\hline & & & & Formic * & 1.99 & 79.35 & $0.32-1.45$ \\
\hline \multirow{3}{*}{40} & \multirow{3}{*}{40} & \multirow{3}{*}{20} & \multirow{3}{*}{4.85} & Lactic ** & 0.85 & 24.48 & $0.23-1.02$ \\
\hline & & & & Acetic ** & 1.09 & 6.48 & $0.18-0.84$ \\
\hline & & & & Formic $* *$ & 1.99 & 142.79 & $0.22-1.02$ \\
\hline \multirow{3}{*}{20} & \multirow{3}{*}{80} & \multirow{3}{*}{-} & \multirow{3}{*}{9.56} & Lactic & 0.99 & 20.03 & $0.27-1.42$ \\
\hline & & & & Acetic & 0.75 & 17.66 & $0.42-1.61$ \\
\hline & & & & Formic & 1.65 & 281 & $0.41-1.69$ \\
\hline \multirow{3}{*}{20} & \multirow{3}{*}{-} & \multirow{3}{*}{80} & \multirow{3}{*}{1.65} & Lactic & 1.42 & 0.13 & $0.01-0.25$ \\
\hline & & & & Acetic & 1.01 & 0.11 & $0.03-0.38$ \\
\hline & & & & Formic & 1.19 & 0.57 & $0.09-1.41$ \\
\hline
\end{tabular}

* Third phase formation was observed when using initial acid concentration in the aqueous feed beyond $0.8 \mathrm{~mol} / \mathrm{L}$;

** Third phase formation was observed for all initial acid concentration.

The loading ratio expresses the ratio of acid concentration in the solvent phase to the solvent concentration, the data show that the loading ratio increases with decreasing TOA concentration and increases with increasing acid concentration.

As expected from physical extraction, the stoichiometric equilibrium constant of lactic acid increases with increasing 1-octanol concentration. The maximum $K_{E}$ was found for the solvent composition of $40 \mathrm{wt} \% \mathrm{TOA}: 40 \mathrm{wt} \%$ 1-octanol in $n$-undecane at $24 \mathrm{~L} / \mathrm{mol}$ due to a high solvation ability. It is obvious that the polarity of 1-octanol improves the solubility of the acid-amine salt in both, the binary and the ternary solvent system. 1-octanol contributes to the solubility of the acid-amine salt by forming H-bonds, and thus influences the stoichiometric equilibrium constant [38]. Similar 
equilibrium concentrations were obtained for the solvent mixtures containing $20 \mathrm{wt} \%$ TOA in 1-octanol $(\mu=9.56 \mathrm{mPa} \cdot \mathrm{s})$ and $40 \mathrm{wt} \%: 40 \mathrm{wt} \%$ TOA:1-octanol diluted in $n$-undecane $(\mu=4.85 \mathrm{mPa} \cdot \mathrm{s})$. This result signifies the role of the solvent in viscosity control.

\subsection{Selectivity}

The selective separation of lactic acid from a multiple acid feed solution containing formic acid, acetic acid and lactic acid was investigated based on the results for the single acids. To determine the selectivity of the separation, the selectivity was calculated according to Equation (11):

$$
\alpha_{\mathrm{HA} 1 / \mathrm{HA} 2}=\left(\mathrm{c}_{\mathrm{HA} 1, \mathrm{Sol}} / \mathrm{c}_{\mathrm{HA} 1, \mathrm{aq})}\right) /\left(\mathrm{c}_{\mathrm{HA} 2, \mathrm{Sol}} / \mathrm{c}_{\mathrm{HA} 2, \mathrm{aq}}\right)
$$

Figure 5 shows the selectivity of lactic acid for the multiple acid feed solutions with different solvent compositions. The initial acid concentrations are in the same range as found in a fermentation broth [9]. The selectivity of lactic acid increases with increasing of TOA and 1-octanol concentration. However, the results show that lactic acid cannot be separated selectively from the other two acids. This result is consistent with the study of Morales et al. [39]. They investigated the extraction of the single mono-carboxylic acids by using TOA in decanol and dodecane and suggested a more step process for the selective acid extraction with an appropriate solvent composition. Nevertheless, in terms of selective separation of acids from a fermentation broth, the results are of interest. Fermentation produces formic acid with a concentration of $0.04 \mathrm{~mol} / \mathrm{L}$ as a by-product. Formic acid could be extracted prior to lactic acid by the solvent system TOA/1-octanol $/ n$-undecane. Thus, lactic and acetic acid remains in the solution and may then be selectively separated using multi-stage extraction. By varying the solvent phase composition in terms of concentration or/and reactive extractant from the first to the second extraction step, the selectivity can be influenced.

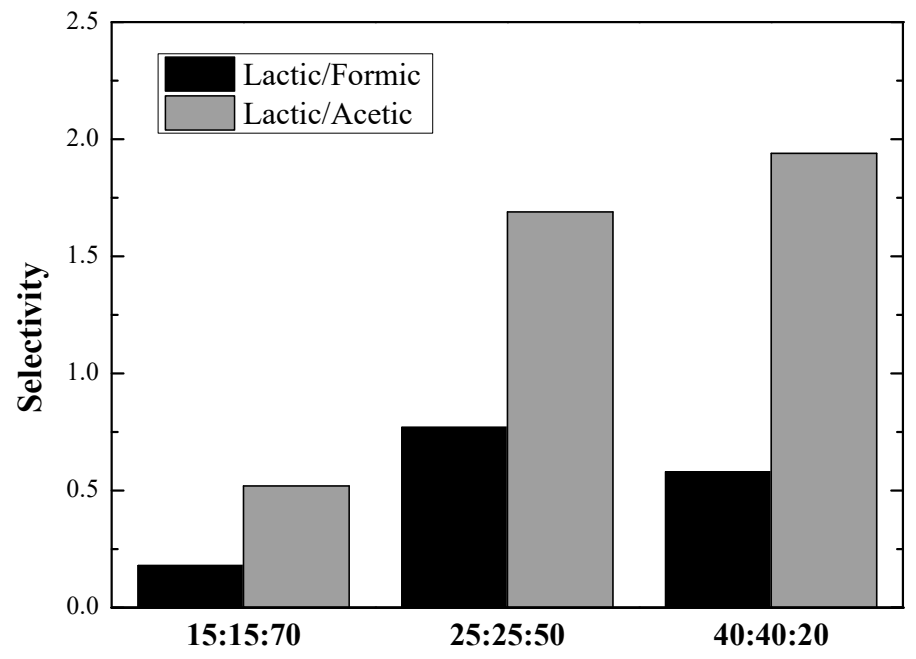

Figure 5. Selectivity of lactic acid against formic acid and acetic acid for different solvent compositions of TOA:1-octanol: $n$-undecane in percentage by weight. $c_{\text {lactic,initial }}=0.7 \mathrm{~mol} / \mathrm{L} ; c_{\text {formic,initial }}=0.04 \mathrm{~mol} / \mathrm{L}$; $c_{\text {acetic,initial }}=0.07 \mathrm{~mol} / \mathrm{L} ; \mathrm{T}=25^{\circ} \mathrm{C}$; ambient pressure.

\subsection{Acids Back-Extraction}

Liquid-liquid extraction of carboxylic acids requires a second separation step for the recovery of the acid from the solvent phase. A stripping solution containing $\mathrm{NaHCO}_{3}$ has been reported to be effective for the back-extraction of lactic acid from laden tri- $n$-octylamine [40]. Hydrogen carbonates do not charge into the solvent phase after back-extraction; hence, the extraction capability of the solvent remains stable.

In this work, back-extraction uses $\mathrm{NaHCO}_{3}$ to liberate the extracted acids from the solvent phase. The phase ratio between the laden solvent and the back-extraction phase was kept constant at 1 by 
weight. Figure 6 shows the back-extraction efficiency of a multiple acid feed containing lactic acid, formic acid and acetic acid. Evaluation of the efficiency follows the same methodology as described in Section 2.3. Similar to the extraction step, the back-extraction relates to the $\mathrm{pK}_{\mathrm{a}}$ value and follows the order formic acid $>$ lactic acid $>$ acetic acid. The degree of back-extraction by means of basic property depends on the equilibrium $\mathrm{pH}$ of the aqueous solution [40]. The present study used a concentration of $1 \mathrm{~mol} / \mathrm{L} \mathrm{NaHCO}$, which leads to a $\mathrm{pH}$ value of 12.2 , the $\mathrm{pH}$ remained the same also in equilibrium. However, for the back-extraction from multiple acids-laden solvent, this topic needs to be further studied.

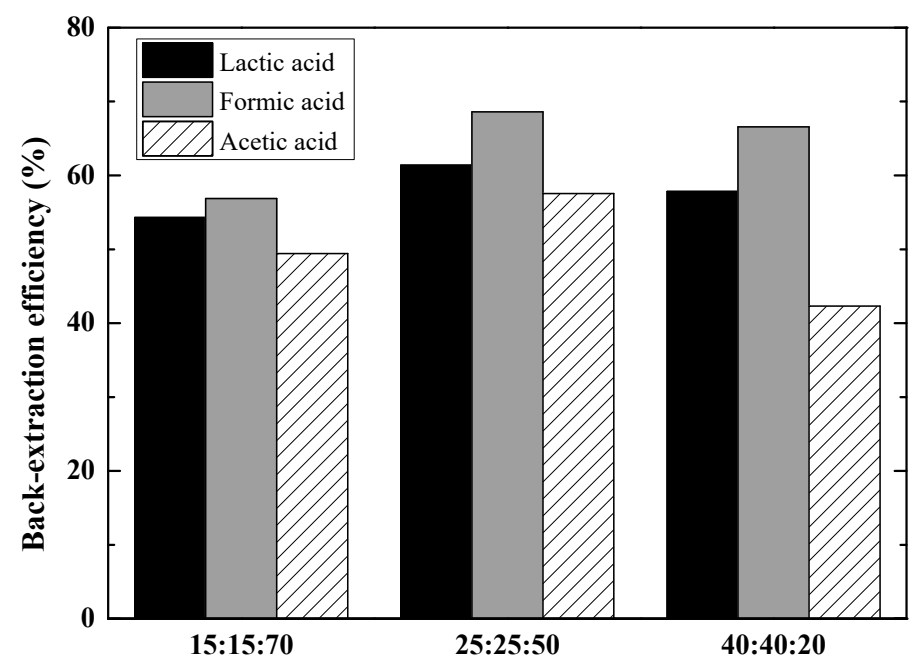

Figure 6. Back-extraction efficiency of lactic acid, formic acid and acetic acid from a multiple feed for different solvent compositions of TOA:1-octanol: $n$-undecane in percent by weight, stripping phase $=$ $1 \mathrm{~mol} / \mathrm{L} \mathrm{NaHCO} 3 ; \mathrm{T}=25^{\circ} \mathrm{C}$; ambient pressure

\section{Conclusions}

Liquid-liquid extraction is a potential unitary operation for the recovery of carboxylic acids from a fermentation broth. In this work, the extraction of lactic acid, formic acid and acetic acid by using single, binary and ternary solvent compositions of TOA; 1 -octanol and $n$-undecane were investigated. Physical extraction by 1 -octanol and $n$-undecane shows disadvantages in terms of extraction efficiency and selectivity compared to reactive extraction. The phase equilibria data showed an increasing acid affinity toward the solvent when increasing the TOA and 1-octanol concentration. With decreasing initial acid concentration an increase in the extraction efficiency, which indicates an applicability for reactive extraction for the isolation of acids from dilute aqueous solutions was observed. The stoichiometric extraction equilibrium constant was evaluated by applying the law of mass action. The calculated equilibrium constant data fit well to the experimental data for binary and ternary solvent systems. The behavior of 1-octanol and $n$-undecane was found to be similar in both binary and ternary solvent systems. 1-octanol influences the extraction equilibrium by its polarity and enhances the solubility of the acid-amine salt in the solvent phase, whereas, $n$-undecane decreases the solvent viscosity without an increase in the extraction efficiency.

The highest equilibrium constant of lactic acid was found at 40:40 TOA:1-octanol by weight diluted in $n$-undecane. However, the selective separation of lactic acid from a mixture of lactic acid, formic acid and acetic acid is not possible. Third phase formation was found for solvents having a TOA beyond $40 \mathrm{wt} \%$. The tendency to form a third phase increases with increasing acid concentration in the feed phase. Back-extraction from the laden solvent phase was performed with sodium hydrogen carbonate, and it was found to depend, in the same way as the extraction, on the acid $\mathrm{pK}_{\mathrm{a}}$. 
Author Contributions: The authors contributed to the paper in the following way: Conceptualization, M.K.; methodology, M.K. and N.M.; software, N.M.; validation, M.K., N.M.; formal analysis, N.M.; investigation, N.M.; resources, M.S.; data curation, N.M. and M.K.; writing—original draft preparation, N.M.; writing-review and editing, M.K. and M.S.; visualization, N.M.; supervision, M.K.; project administration, M.K.; funding acquisition, N.M.

Funding: This research received no external funding.

Acknowledgments: Research reported in this publication was supported by the ASEAN-European Academic University Network (ASEA-UNINET).

Conflicts of Interest: The authors declare no conflict of interest.

\section{Nomenclature}

$\begin{array}{ll}\text { aq } & \text { aqueous phase } \\ c & \text { concentration } \\ D & \text { dimerization constant } \\ E & \text { extraction efficiency } \\ \text { HA } & \text { carboxylic acid } \\ K_{D} & \text { distribution coefficient } \\ K_{\text {diss }} & \text { Dissociation constant } \\ K_{E} & \text { extraction equilibrium constant } \\ \text { LA } & \text { Lactic acid } \\ m & \text { mass } \\ n & \text { degree of association } \\ \text { nondiss } & \text { non-dissociated } \\ P & \text { partition coefficient } \\ \text { sol } & \text { solvent phase } \\ Z & \text { loading } \\ 0, \text { in } & \text { initial concentration } \\ \alpha & \text { Degree of dissociation }\end{array}$

\section{References}

1. Davis, J. Lactic Acid Market Size Worth over 6 Billion Dollars by 2024 . Available online: https://globenewswire.com/news-release/2016/11/09/888221/0/en/Lactic-Acid-Market-size-worthover-6-billion-by-2024-Global-Market-Insights-Inc.html (accessed on 12 June 2017).

2. James, S. Lactic Acid and Poly Lactic Acid (PLA) Market to Reach 4,312.2 Million dollars and 2,169.6 Million dollars Respectively by 2020. Available online: http://www.reuters.com/article/idUSnMKWSZm27a+1f0+ MKW20150714 (accessed on 12 June 2017).

3. Jantasee, S.; Kienberger, M.; Mungma, N.; Siebenhofer, M. Potential and assessment of lactic acid production and isolation-A review. J Chem. Technol. Biotechnol. 2017. [CrossRef]

4. Castillo Martinez, F.A.; Balciunas, E.M.; Salgado, J.M.; Dominguez Gonzalez, J.M.; Converti, A.; de Souza Oliveira, R.P. Lactic acid properties, applications and production: A review. Trends Food Sci. Technol. 2013, 30, 70-83. [CrossRef]

5. Wang, Y.; Tashiro, Y.; Sonomoto, K. Fermentative production of lactic acid from renewable materials: Recent achievements, prospects, and limits. J. Biosci. Bioeng. 2015, 119, 10-18. [CrossRef]

6. López-Garzón, C.S.; Straathof, A.J.J. Recovery of carboxylic acids produced by fermentation. Biotechnol. Adv. 2014, 32, 873-904. [CrossRef]

7. Taskila, S.; Ojamo, H. The Current Status and Future Expectations in Industrial Production of Lactic Acid by Lactic Acid Bacteria. In Lactic Acid Bacteria-R \& D for Food, Health and Livestock Purposes; InTech: Rijeka, Croatia, 2013. Available online: https://www.intechopen.com/books/lactic-acid-bacteria-r-d-for-food-healthand-livestock-purposes/the-current-status-and-future-expectations-in-industrial-production-of-lacticacid-by-lactic-acid-ba (accessed on 3 December 2018).

8. Abdel Rahman, M.A.; Tashiro, Y.; Sonomoto, K. Recent advances in lactic acid production by microbial fermentation processes. Biotechnol. Adv. 2013, 31, 877-902. [CrossRef] 
9. Lee, H.J.; Xie, Y.; Koo, Y.M.; Wang, N.H.L. Separation of Lactic Acid from Acetic Acid Using a Four-Zone SMB. Biotechnol. Prog. 2004, 20, 179-192. [CrossRef]

10. Patel, M.; Bassi, A.S.; Zhu, J.J.; Gomaa, H. Investigation of a Dual-Particle Liquid - Solid Circulating Fluidized Bed Bioreactor for Extractive Fermentation of Lactic Acid. Biotechnol. Prog. 2008, 24, 821-831. [CrossRef]

11. Dey, P.; Linnanen, L.; Pal, P. Separation of lactic acid from fermentation broth by cross flow nanofiltration: Membrane characterization and transport modelling. Desalination 2012, 288, 47-57. [CrossRef]

12. Habova, V.; Melzoch, K.; Rychtera, M.; Pribyl, L.; Vladimir, M. Application of electrodialysis for lactic acid recovery. Czech J. Food Sci. 2001, 19, 73-80. [CrossRef]

13. Woodley, J.M.; Bisschops, M.; Straathof, A.J.J.; Ottens, M. Perspective Future directions for in-situ product removal (ISPR). J. Chem. Technol. Biotechnol. 2008, 82, 121-123. [CrossRef]

14. Anvari, M.; Khayati, G. In situ recovery of 2,3-butanediol from fermentation by liquid-liquid extraction. J. Ind. Microbiol. Biotechnol. 2009, 36, 313-317. [CrossRef] [PubMed]

15. Bart, H.-J. Reactive Extraction. In Reactive Extraction; Dechema: Frankfurt, Germany, 2001; pp. $10-11$. ISBN 978-3-642-07430-1.

16. Eyal, A.M.; Canari, R. pH Dependence of Carboxylic and Mineral Acid Extraction by Amine-Based Extractants: Effects of pKa, Amine Basicity, and Diluent Properties. Ind. Eng. Chem. Res. 1995, 34, 1789-1798. [CrossRef]

17. Leis, D.; Lauß, B.; Macher-ambrosch, R.; Pfennig, A.; Nidetzky, B.; Kratzer, R. Integration of whole-cell reaction and product isolation: Highly hydrophobic solvents promote in situ substrate supply and simplify extractive product isolation. J. Biotechnol. 2017, 257, 110-117. [CrossRef] [PubMed]

18. Kienberger, M.; Hackl, M.; Siebenhofer, M. Emulsion Prevention with Supported Liquid Membrane Permeation. Chem. Eng. Technol. 2018, 41, 504-508. [CrossRef]

19. Canari, R.; Eyal, A.M. Selectivity in Monocarboxylic Acids Extraction from Their Mixture Solutions Using an Amine-Based Extractant: Effect of pH. Ind. Eng. Chem. Res. 2003, 42, 1301-1307. [CrossRef]

20. Datta, D.; Kumar, S.; Uslu, H. Status of the Reactive Extraction as a Method of Separation. J. Chem. 2014, 2015, 1-16. [CrossRef]

21. Tamada, J.A.; Kertes, A.S.; King, C.J. Extraction of Carboxylic Acids with Amine Extractants. 1. Equilibria and Law of Mass Action Modeling. Ind. Eng. Chem. Res. 1990, 29, 1319-1326. [CrossRef]

22. Udachan, I.S.; Sahoo, A.K. A studyof parameters affecting the solvent extraction of lactic acid from fermentation broth. Braz. J. Chem. Eng. 2014, 31, 821-827. [CrossRef]

23. Han, D.H.; Hong, Y.K.; Hong, W.H. Separation Characteristics of Lactic Acid in Reactive Extraction and Stripping. Korean J. Chem. Eng. 2000, 17, 528-533. [CrossRef]

24. Qin, W.; Li, Z.; Dai, Y. Extraction of Monocarboxylic Acids with Trioctylamine: Equilibria and Correlation of Apparent Reactive Equilibrium Constant. Ind. Eng. Chem. Res. 2003, 42, 6196-6204. [CrossRef]

25. Wasewar, K.L.; Keshav, A. Seema. Physical extraction of propionic acid. Int. J. Res. Rev. Appl. Sci. 2010, 3, 290-302.

26. Wang, Y.; Cai, D.; He, M.; Wang, Z.; Qin, P.; Tan, T. Open fermentative production of 1-lactic acid using white rice bran by simultaneous saccharification and fermentation. Bioresour. Technol. 2015, 198, 664-672. [CrossRef]

27. Maurer, G. Modeling the liquid-liquid equilibrium for the recovery of carboxylic acids from aqueous solutions. Fluid Phase Equilib. 2006, 241, 86-95. [CrossRef]

28. Painer, D.; Lux, S.; Grafschafter, A.; Toth, A.; Siebenhofer, M. Isolation of Carboxylic Acids from Biobased Feedstock. Chemie-Ingenieur-Technik 2017, 89, 161-171. [CrossRef]

29. Labbaci, A.; Kyuchoukov, G.; Albet, J.; Molinier, J. Detailed investigation of lactic acid extraction with tributylphosphate dissolved in dodecane. J. Chem. Eng. Data 2010, 55, 228-233. [CrossRef]

30. Thakre, N.; Prajapati, A.K.; Mahapatra, S.P.; Kumar, A.; Khapre, A.; Pal, D. Modeling and Optimization of Reactive Extraction of Citric Acid. J. Chem. Eng. Data 2016, 61, 2614-2623. [CrossRef]

31. Siebenhofer, M.; Marr, R. Acid extraction by amines. In Proceedings of the ISEC, Denver, CO, USA, 28 August 1983.

32. Kyuchoukov, G.; Labbaci, A.; Albet, J.; Molinier, J. Simultaneous influence of active and "Inert" diluents on the extraction of lactic acid by means of Tri-n-octylamine (TOA) and Tri-wo-octylamine (TIOA). Ind. Eng. Chem. Res. 2006, 45, 503-510. [CrossRef]

33. Yamamoto, T.; Kojima, K.; Mori, H.; Kawasaki, H.; Sayama, M. Extraction of lactic acid using long chain amines dissolved in non-polar diluents. J. Chem. Eng. Jpn. 2011, 44, 949-956. [CrossRef] 
34. Kislik, V. Solvent Extraction, 1st ed.; Elsevier: Amsterdam, The Netherlands, 2012; ISBN 9780444537782.

35. Schulz, R.; Van Den Bongard, R.; Islam, J.; Zeiner, T. Purification of Terpenyl Amine by Reactive Extraction. Ind. Eng. Chem. Res. 2016, 55, 5763-5769. [CrossRef]

36. Kyuchoukov, G.; Marinova, M.; Molinier, J.; Albet, J.; Malmary, G. Extraction of lactic acid by means of a mixed extractant. Ind. Eng. Chem. Res. 2001, 40, 5635-5639. [CrossRef]

37. Lux, S.; Siebenhofer, M. Investigation of liquid-liquid phase equilibria for reactive extraction of lactic acid with organophosphorus solvents. J. Chem. Technol. Biotechnol. 2013, 88, 462-467. [CrossRef]

38. Keshav, A.; Chand, S.; Wasewar, K.L. Recovery of propionic acid from aqueous phase by reactive extraction using quarternary amine (Aliquat 336) in various diluents. Chem. Eng. J. 2009, 152, 95-102. [CrossRef]

39. Morales, A.F.; Albet, J.; Kyuchoukov, G.; Malmary, G.; Molinier, J. Influence of extractant (TBP and TOA), diluent, and modifier on extraction equilibrium of monocarboxylic acids. J. Chem. Eng. Data 2003, 48, 874-886. [CrossRef]

40. Kyuchoukov, G.; Yankov, D. Theoretical and experimental study of lactic acid stripping from loaded organic phase. Ind. Eng. Chem. Res. 2010, 49, 8238-8243. [CrossRef]

(C) 2019 by the authors. Licensee MDPI, Basel, Switzerland. This article is an open access article distributed under the terms and conditions of the Creative Commons Attribution (CC BY) license (http://creativecommons.org/licenses/by/4.0/). 